\title{
Water intake after septal damage in Long-Evans hooded rats and muricide, irritability to handling, and open-field activity
}

\author{
B. MICHAEL THORNE, KER-NENG LIN, and MAXIE L. WEAVER \\ Mississippi State University, Mississippi State, Mississippi
}

\begin{abstract}
Water intake, muricidal behavior, irritability to handling, and open-field activity were assessed in Long-Evans male hooded rats subjected to either septal damage or control operations. Because of a failure to observe increased water intake after septal damage, it was concluded that increased water intake was not necessary for the display of either the transient irritability or the open-field inactivity usually seen in rats with septal damage. Muricidal behavior was not seen in the present study.
\end{abstract}

Damage to the septal area in the rat is associated with a variety of behavioral changes, including transient changes in irritability to handling (e.g., Brady \& Nauta, 1953; King, 1958; Latham \& Thorne, 1974; Wallace \& Thorne, 1978), increases in water intake (e.g., Blass \& Hanson, 1970; Lorens \& Kondo, 1969; Stricker, 1978), and changes in open-field activity (e.g., Jonason \& Enloe, 1971; Kemble \& Nagel, 1975; Wallace \& Thorne, 1978). In some studies, an increase in mouse-killing behavior has been seen (e.g., Latham \& Thorne, 1974; Miczek \& Grossman, 1972), but this is not an invariant finding (e.g., Malick, 1970; Thorne, Aaron, \& Latham, 1974).

Flynn, Hawkins, and Tedford (1979) found a relationship between two behavioral changes commonly seen after septal ablation, hyperdipsia and increased shock-elicited fighting. Specifically, restricting septally lesioned rats to preoperative water intake resulted in a dramatic decline in "aggression" scores. The authors concluded that future studies must consider the contribution of hyperdipsia to changes in aggression seen after septal damage.

The present study was designed to test the generality of Flynn et al.'s (1979) findings. That is, is overhydration after septal damage correlated only with changes in shock-elicited fighting or is it related to other behavioral changes as well? To test this question, we compared septally lesioned animals with or without restricted water intake on irritability to handling, muricidal behavior, and openfield activity.

In a previous study (Buteau \& Thorne, unpublished observations), we did not observe an increase

This research was partially supported by an institutional grant from NSF to MSU. Requests for reprints may be sent to: B. Michael Thorne, Drawer PF, Mississippi State, Mississippi 39762. in postoperative water consumption after septal lesions. In an attempt to rectify this problem, we decided to adopt operation parameters from a study in which a very high postoperative water intake was seen (Stricker, 1978).

\section{METHOD}

\section{Animals}

The animals were 30 adult male Long-Evans rats, approximately 3 months old at the beginning of the experiment. All rats were drawn from the animal colony maintained by the Psychology Department at Mississippi State University and were first-generation offspring of breeding stock obtained from Blue Spruce Farms, Altamont, New York. Because of a postoperative infection, one subject was discarded.

All animals were multiply housed until 1 week prior to surgery. At that time, the rats were placed in individual hanging cages measuring $17.78 \times 25.40 \times 17.78 \mathrm{~cm}$. Ad-lib food and water conditions were maintained throughout the study, except for one group whose water intake was restricted postoperatively. A 12:12 light-dark cycle was in effect in the laboratory.

The 29 subjects were assigned to one of the following groups on the basis of preoperative water intake: operated control (Group OC, $N=10$ ), septal lesion with restricted water intake (Group SEP-RW, $N=10$ ), and septal lesion with free water intake (Group SEP-FW, $\mathbf{N}=9$ ). A one-way analysis of variance revealed no significant differences between groups in terms of preoperative weight (mean $=432.8 \mathrm{~g}$, range from 356 to $529 \mathrm{~g}$ ).

\section{Surgery and Histology}

The rats were deeply anesthetized with an ip injection of chloral hydrate, their heads were shaved, and each was given an intramuscular injection $(0.2 \mathrm{cc})$ of Duracilin. The heads of the animals were secured in the head holder of a Baltimore stereotaxic instrument, and an incision was made along the midline of the scalp. A line was etched on the skull perpendicular to bregma to serve as a reference point for aligning the anteriorposterior coordinates. A hole of approximately $3 \mathrm{~mm}$ was drilled through the skull, with bregma at its center. Using a Stoelting lesion-producing device, lesions were made via a stainless steel electrode insulated except for $0.5 \mathrm{~mm}$ at the tip.

With the skull's surface horizontal, the coordinates were 1.0 $2.0 \mathrm{~mm}$ anterior to bregma, $0.5 \mathrm{~mm}$ lateral to the midsagittal sinus, and $5.2 \mathrm{~mm}$ ventral to the brain's surface. The current 
employed was $2.0 \mathrm{~mA}$ for $20 \mathrm{sec}$. Animals in Group OC were subjected to the entire operative procedure except that the electrode was not inserted into the brain.

The wounds were closed with stainless steel autoclips. Each animal was then returned to its cage and allowed 7 days to recuperate before testing began.

Approximately $24 \mathrm{~h}$ after the last day of testing, the animals were sacrificed with an overdose of chloral hydrate. The brains were immediately extracted and fixed in a $10 \%$ Formalin solution for at least $24 \mathrm{~h}$ prior to slicing. Each brain was frozen using a Super Histo-Freeze, and slices approximately $100 \mu$ thick were made with an AO Spencer sliding microtome. Several sections through the area of greatest damage were saved and stored in water. They were next placed on glass slides and projected, after $10 \times$ enlargement, onto photographic paper. The resulting prints were used to determine the brain areas damaged and to rank the subjects in terms of extent of damage to the septal nuclei.

\section{Procedure}

On the day after the animals were singly housed, water intake was recorded, and daily recording continued throughout the study. The recording was performed at about the same time each day. A preoperative daily mean water intake was computed for each animal, and the result was used in assigning animals to operative groups.

Postoperatively, recording of water intake continued as before, except that rats in Group SEP-RW received only their preoperative average plus $5 \mathrm{ml}$. The additional $5 \mathrm{ml}$ was given because the physical properties of the bottle, stopper, and drinking tube prevent all of the water from being drained. The extra water insured that each RW animal could ingest its preoperative average.

On Postoperative Day 7, a 24-h test of muricidal behavior was given with an initial 20-min observation period. In the test, an albino mouse was placed into the cage of each rat, and the incidence of killing and latency to kill during the first 20 minutes were recorded. At the end of $24 \mathrm{~h}$, any live mice or the remains of any dead ones were removed from the cage. Any kills taking place after the 20-min observation period were assigned a 24-h latency. All testing took place during the light portion of the light-dark cycle.

On Postoperative Days 8-11, handling tests were administered. Because of the tendency of the septal rat to leap from an opened cage, a clipboard was placed over the top of the cage as it was carried from the cage rack to the table on which the handling test was conducted. The handling test was the 5-component scale used by Thorne, Aaron, and Latham (1973). The components were as follows: (1) reaction to perioral pencil presentation, (2) reaction to a pencil tap on the flank, (3) ease of capture, (4) ease of handling, and (5) amount of vocalization. Each component was rated on a 4-point scale (0-3), and each animal was given a daily score based on the summed ratings. The length of the test was $1 \mathrm{~min}$, and the components were administered in the order listed.

Activity was assessed in an open-field apparatus immediately following the handling test. The box measured $76.2 \times 76.2 \times$ $25.4 \mathrm{~cm}$, was painted flat black, and the floor was divided by white lines into 25 equal squares. Wire mesh covered the top. The number of squares crossed and the number of rearings (standing on the hind legs) during a 1-min period were recorded. The apparatus was cleaned frequently, and the order of testing was varied daily.

Frequent interobserver reliability measurements were made by having an independent observer score the handling test and open-field activity. The reliability for the summed daily handling scores was $r_{S}=0.86, p<.01$, while that for open-field activity was even higher (horizontal, $r=0.98, p<.01$; rearing, $r=0.95$, $\mathrm{p}<.01)$.

All subjects were weighed on the day of sacrifice.

\section{RESULTS}

\section{Histology}

In general, the lesions were placed somewhat anteriorly; they usually extended from about $1 \mathrm{~mm}$ anterior to bregma to $3.5 \mathrm{~mm}$ anterior. The lesions were bounded dorsally by the corpus callosum, laterally by the walls of the lateral ventricles, and ventrally by the base of the brain at the anterior portion of the lesion and by the anterior commissure at the posterior part. In addition to the medial and lateral septal nuclei, which were damaged in all animals, structures sustaining bilateral damage in most rats included the following: nucleus accumbens; hippocampus, pars anterior; nucleus tractus diagonalis; and nucleus preopticus, pars suprachiasmatica. Structures damaged in a few animals in each group were the neocortex, corpus callosum, anterior commissure, nucleus preopticus medialis, and medianus. Figure 1 shows sections from rats with large and small amounts of damage to the septal area from each septal group.

Within each septal group, animals were ranked according to extent of damage to the septal nuclei, and a ranking was made of all the septal animals as well. A Mann-Whitney test comparing the rankings revealed that the septal groups did not differ on the variable of extent of damage to the septal area.

\section{Weight}

One-way analyses of variance revealed no significant differences between the three groups in terms of either preoperative or postoperative weight. The preoperative and postoperative group means were as follows: Group OC, 432.7 and $451.9 \mathrm{~g}$; Group RW, 427.7 and $424 \mathrm{~g}$; Group FW, 438.7 and $422.8 \mathrm{~g}$.

Within each group, dependent $t$ tests were used to assess postoperative weight change. The results of the tests indicated a significant gain in weight for Group $\mathrm{OC}[\mathrm{t}(9)=-5.63, \mathrm{p}<.01]$ and a significant weight loss for Group FW $[\mathrm{t}(8)=3.16, \mathrm{p}<.02]$. The slight decline in weight for Group RW was not significant.

\section{Water Intake}

The groups did not differ in terms of preoperative water consumption, and the mean daily intakes were as follows: Group OC, $56.5 \mathrm{ml}$; Group RW, $55.3 \mathrm{ml}$; and Group FW, $54.9 \mathrm{ml}$. Postoperatively, however, a one-way ANOVA revealed evidence for significance between the groups $[F(2,26)=3.62$, $p<.05]$. The postoperative values for septal and control water intake were based on Days 3-12 of the postoperative testing period since water intake was almost always quite low in the immediate postoperative period. Postoperative group means were: 


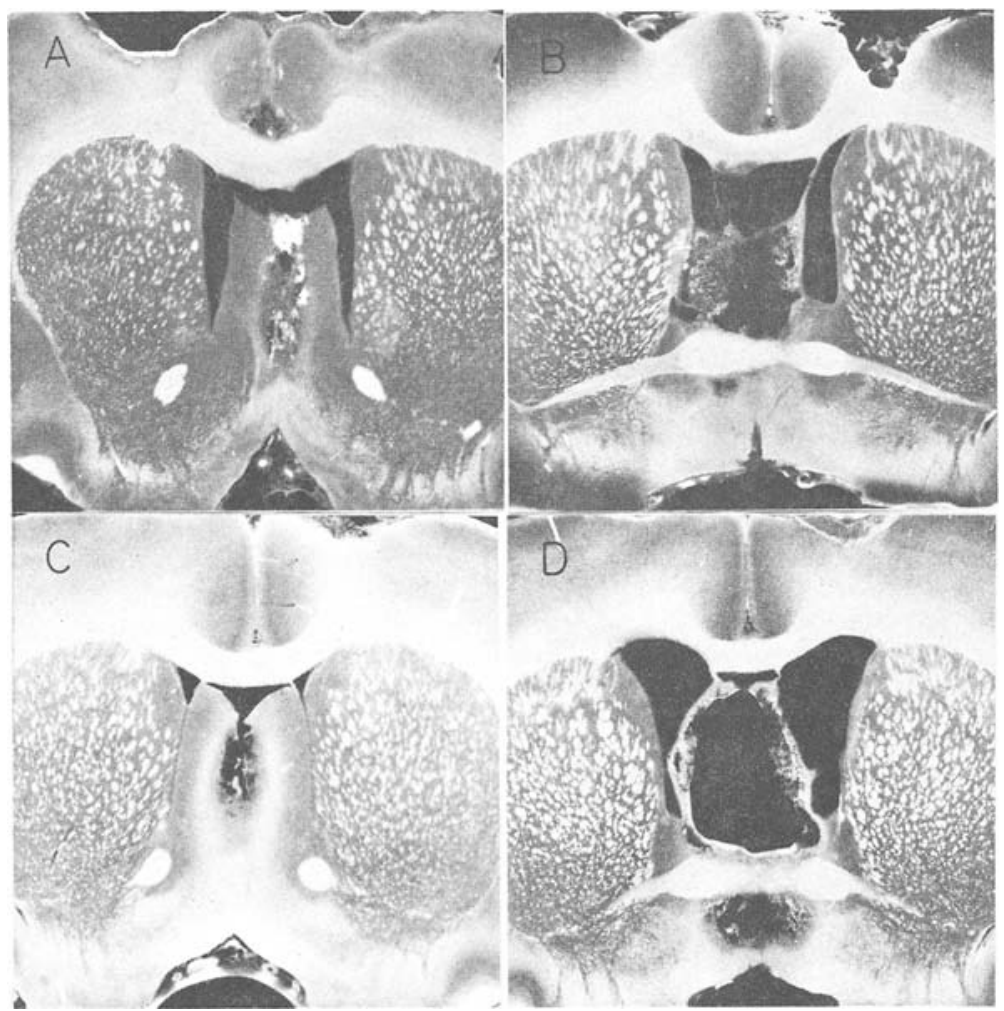

Figure 1. Photographs of unstained sections showing a large and a small septal lesion from animals in each septal group. Sections $A$ and B, small and large septal lesions, respectively, Group SEP-RW; Sections C and D, small and large septal lesions, respectively, Group SEP-FW.

Group OC, $52.3 \mathrm{ml}$; Group RW, $44.35 \mathrm{ml}$; Group FW, $45.3 \mathrm{ml}$.

Further analysis of postoperative intake using the protected t test (Couch, 1982) revealed that both of the septal groups drank significantly less water than the controls [Group OC vs. Group RW, $\mathrm{t}_{\mathrm{p}}(26)$ $=2.48, \mathrm{p}<.02$; Group OC vs. Group FW, $\mathrm{t}_{\mathrm{p}}(26)$ $=2.13, \mathrm{p}<.05]$. The septal groups did not differ.

It could be argued that animals in Group RW might have shown increased water intake if they had been given the opportunity, that is, if their postoperative water had not been restricted to their preoperative average. Arguing against this, however, is the fact that on only 12 of 100 observations (10 rats on 10 days) did animals in Group RW drink as much as their preoperative average. That is, on 88 of 100 samplings, Group RW rats did not consume even the total amount allowed.

Within-group comparisons confirmed the postoperative decline in water intake in the septal groups indicated by the group means. Thus, while Group OC showed no change in water intake, both of the septal groups had a significant decrease [Group RW, $\mathrm{t}(9)=3.54, \mathrm{p}<.01 ;$ Group FW, $\mathrm{t}(8)=3.4, \mathrm{p}<.01]$.

\section{Muricide}

None of the animals killed.

\section{Handling}

Septally lesioned rats were more difficult to handle than control animals. A Kruskal-Wallis one-way ANOVA was used to compare the treatment groups, and a significant result was found in terms of the summed 4-day scores $[H(2)=13.06, p<.01]$. Pairwise comparisons were made using the MannWhitney test, and both septal groups differed significantly from the controls (Group OC vs. RW, $\mathrm{U}=12, \mathrm{p}<.02$; Group $\mathrm{OC}$ vs. $\mathrm{FW}, \mathrm{U}=4.5, \mathrm{p}<$ $.002)$ but not from each other. The median 4-day totals for each group were: Group OC, 4; Group RW, 16.5; and Group FW, 21. The correlations between extent of damage and handling scores were not significant for either septal group.

\section{Open-Field Activity (Squares Crossed)}

Rats in the control group were much more active than the septally lesioned animals. The KruskalWallis test revealed significant intergroup differences $[H(2)=13.81, p<.01]$. Individual comparisons indicated that the septal groups were significantly different from the control group (OC vs. FW, $U=6, p<.002 ; O C$ vs. $R W, U=8, p<.002$ ) but not from each other. The group means for summed 4-day scores were: Group OC, 53.1; Group RW, 6.0; and Group FW, 3.0. The corre- 
lations between extent of damage and horizontal activity scores were not significant for either septal group.

\section{Open-Field Activity (Rearing)}

The results for rearing were identical to those for horizontal activity. An overall test revealed significant between-group differences $[H(2)=19.1$, $\mathrm{p}<.01]$. Using individual comparisons, the septal groups differed significantly from Group OC (OC vs. FW or $\mathrm{OC}$ vs. $\mathrm{RW}, \mathrm{U}=0, \mathrm{p}<.002$ ) but not from each other. The group means for summed 4-day scores were: Group OC, 22.1; Group RW or Group FW, 1.6. Correlations with extent of damage were not significant.

\section{DISCUSSION}

This experiment attempted to answer the question of the relationship between enhanced water intake after septal damage and certain other behavioral changes often seen. Although no evidence for enhanced water intake was noted in contrast to a variety of other reports (e.g., Blass \& Hanson, 1970; Lorens \& Kondo, 1969; Stricker, 1978), a number of conclusions can still be made.

For example, increased water intake is not necessary for the transient irritability to handling seen after septal damage in the rat (e.g., Brady \& Nauta, 1953; King, 1958; Latham \& Thorne, 1974). Septally damaged rats in this experiment were much harder to handle than controls but showed decreases in water intake.

Similarly, increased water intake is not necessary for the decreases in open-field activity usually seen in rats following septal damage (e.g., Jonason \& Enloe, 1971; Kemble \& Nagel, 1975; Wallace \& Thorne, 1978). Septally lesioned animals in this experiment showed dramatic reductions in activity relative to controls without increases in water intake.

No conclusions can be drawn, however, about a possible relationship between enhanced water intake and muricide. In contrast to some reports (e.g., Latham \& Thorne, 1974; Miczek \& Grossman, 1972), rats in the present study did not kill after septal lesions. In view of Wallace and Thorne's (1978) demonstration of the importance of lesion locus for mouse killing after septal damage and of the lack of an increase in water intake in this study, it is possible that lesions resulting in enhanced water intake would also produce killing behavior.

In general, the results of the present experiment support the findings of most previous research on septal damage in the rat, their handling characteristics and open-field activity. The one major discrepancy was the failure to obtain evidence for enhanced water intake. The variability in lesion size and locus in this study decreases the likelihood that the variable of lesion locus can account for our failure to see increased water consumption. This observation is further strengthened by the unpublished findings of Buteau and Thorne, none of whose septally damaged rats increased water intake. In addition, the coordinates used for producing the lesions were different from those in this experiment, with resulting differences in size and locus of destruction.

If differences in lesion locus cannot account for the behavioral discrepancies, what other methodological differences might be involved? One possible explanation is that we used Long-Evans hooded rats, while many studies in which enhanced water consumption has been found have used albinos of either the Wistar or the Sprague-Dawley strain (e.g., Blass \& Hanson, 1970; Flynn et al., 1979; Lorens \& Kondo, 1969). In three studies of the effects of septal damage on water intake in hooded rats (Dickinson, 1973; Lubar, Herrmann, Moore, \& Shouse, 1973; Singh \& Meyer, 1968), two reported increased water intake under food-deprivation conditions. Lubar et al. reported that septal animals drank from water sources more often than did other rats, but they did not actually measure water intake. Thus, it is conceivable that LongEvans rats, unlike albinos, display increased water intake only under unusual circumstances, for example, food deprivation.

\section{REFERENCES}

Blass, E. M., \& Hanson, G. G. Hyperdipsia in the rat following septal lesions. Journal of Comparative and Physiological Psychology, 1970, 70, 87-93.

Brady, J. V., \& NaUta, W. J. H. Subcortical mechanisms in emotional behavior: Affective changes following septal forebrain lesions in the albino rat. Journal of Comparative and Physiological Psychology, 1953, 46, 339-346.

Couch, J. V. Fundamentals of statistics for the behavioral sciences. New York: St. Martin's Press, 1982.

Dickinson, A. Prandial drinking following septal lesions in rats. Physiology \& Behavior, 1973, 10, 335-338.

Flynn, W. E., Hawkins, M. F., \& Tedford, W. H. The role of hyperdipsia in aggression following septal lesions in rats. Journal of Comparative and Physiological Psychology, 1979, 93, 1053-1066.

Jonason, K. R., \& Enloe, C. J. Alterations in social behavior following septal and amygdaloid lesions in the rat. Journal of Comparative and Physiological Psychology, 1971, 75, 286-301.

Kemble, E. D., \& Nagel, J. A. Persistent depression of rearing behavior in rats after extensive septal lesions. Journal of Comparative and Physiological Psychology, 1975, 89, 747-758.

King, F. A. Effects of septal and amygdaloid lesions on emotional behavior and conditioned avoidance response in the rat. Journal of Nervous and Mental Disease, 1958, 126, 57-63.

Latham, E. E., \& Thorne, B. M. The effect of handling, strain, and septal lesions on muricidal behavior in the rat. Physiology \& Behavior, 1974, 12, 521-526.

Lorens, S. A., \& Kondo, C. Y. Effects of septal lesions on 
food and water intake and operant responding for food. Physiology \& Behavior, 1969, 4, 729-732.

Lubar, J. F., Herrmann, T. F., Moore, D. R., \& Shouse, M. N. Effect of septal and frontal ablations on species-typical behavior in the rat. Journal of Comparative and Physiological Psychology, 1973, 83, 260-270.

Malick, J. B. A behavioral comparison of three lesion-induced models of aggression in the rat. Physiology \& Behavior, 1970, 5, 679-681.

MiczeK, K. A., \& Grossman, S. P. Effects of septal lesions on inter- and intraspecies aggression in rats. Journal of Comparative and Physiological Psychology, 1972, 79, 37-45.

Singh, D., \& MEYER, D. R. Eating and drinking by rats with lesions of the septum and the ventromedial hypothalamus. Journal of Comparative and Physiological Psychology, 1968, 65, 163-166.
Stricker, E. M. Excessive drinking by rats with septal lesions during hypovolemia induced by subcutaneous colloid treatment. Physiology \& Behavior, 1978, 21, 905-907.

Thorne, B. M., Aaron, M., \& Latham, E. E. Effects of olfactory bulb ablation upon emotionality and muricidal behavior in four rat strains. Journal of Comparative and Physiological Psychology, 1973, 84, 339-344.

Thorne, B. M., Aaron, M., \& Latham, E. E. Olfactory system damage in rats and emotional, muricidal, and rat pup killing behavior. Physiological Psychology, 1974, 2, 157-163.

Wallace, T., \& Thorne, B. M. The effect of lesions in the septal region on muricide, irritability, and activity in the LongEvans rat. Physiological Psychology, 1978, 6, 36-42.

(Manuscript received July 14, 1982; revision accepted for publication January $26,1983$. ) 